\title{
From Arctic Science to Global Policy - Addressing Multiple Stressors Under the Stockholm Convention
}

\author{
Eirik Hovland Steindal
}

Norwegian Institute for Water Research (NIVA) and Department of International

Environment and Development Studies, Norwegian University of Life Sciences, Norway

\section{Marianne Karlsson}

Norwegian Institute for Water Research (NIVA), Norway

\section{Erlend A. T. Hermansen \\ CICERO Center for International Climate Research, Norway}

\author{
Trude Borch \\ Akvaplan-niva, Norway
}

\section{Froukje Maria Platjouw}

Norwegian Institute for Water Research (NIVA) and Scandinavian Institute for Maritime Law, University of Oslo, Norway

\begin{abstract}
Rapid climate change in the Arctic triggers the remobilization of chemical pollution, increasing its exposure and potential impacts in the region. While scientific knowledge on multiple stressors, including the interlinkages between climate change and hazardous chemicals, is increasing, it has proven challenging to translate this knowledge into policy. This study analyzes the process of translating Arctic scientific knowledge on multiple stressors into global policy by focusing on the development of a guidance document under the Stockholm Convention on Persistent Organic Pollutants (POPs). Through document analysis and key informant interviews, we focus particularly on the role of the Arctic Council working group AMAP in synthesizing, translating and communicating science on multiple stressors to policy makers. We draw on the theoretical framework of formalization (how and by whom knowledge is summarized for policy) and separation (the relative distance between science and policy) to analyze the science-to-policy interface. Our analysis of the
\end{abstract}

\footnotetext{
^Correspondence to: Eirik Hovland Steindal, email: ehs@niva.no 
phases leading up to the guidance document show that AMAP has dynamically moved between different degrees of separation and formalization. Orchestrating the interplay between scientists and policy makers, the working group has put multiple stressors on the political agenda internationally. AMAP has thereby contributed to turn Arctic science into global policy through the guidance document. We conclude by illustrating several constraints in terms of the implementation of actual policy, which we argue is due to an increasing degree of formalization in the last phase and a general unreadiness of contemporary governance systems to address multiple stressors.

Keywords: multiple stressors, climate change, Persistent Organic Pollutants, POPs, Stockholm Convention, science policy, Arctic Council, Arctic Monitoring and Assessment Programme (AMAP), international negotiations

Responsible Editor: Øyvind Ravna, Faculty of Law, UiT The Arctic University of Norway

Received: October 2020; Accepted: January 2021; Published: March 2021

\section{Introduction}

The Arctic environment is experiencing rapid, complex and unprecedented environmental change and stress. ${ }^{1}$ Anthropogenic environmental stressors are jeopardizing the resilience of ecosystems in the region, individually and in complex interactions. ${ }^{2}$ The transboundary nature of stressors also challenges existing governance systems, which are commonly sector-based and issue specific. ${ }^{3}$ These governance systems are not rigged to address and alleviate interacting and systemic stressors. The complexity of multiple environmental stressors and speed of change in the Arctic makes it particularly challenging to communicate scientific findings to policy makers and to translate this science into policy. ${ }^{4}$ It is often difficult to identify causal relationships in multiple stressor interactions and they involve a wide range of uncertainty, which makes the topic important to study from a science-policy interface perspective. ${ }^{5}$ This paper analyzes a multi stressor science-policy process under the Stockholm Convention (SC) on Persistent Organic Pollutants (POPs). As one of the few actual examples of a policy addressing the interaction of multiple stressors, we argue that this case provides important lessons on how science on multiple stressors may be translated into international policy.

POPs are a group of hazardous chemicals that are defined by their persistence in the environment, their tendency to bioaccumulate in the food chain and their toxicity to living organisms. ${ }^{6}$ In addition, these chemicals travel across borders by air, water currents or biotic vectors. These traits make POPs a major concern for both human health and ecosystems. Climate change effects may exacerbate the hazard potential from POPs due to increasing temperatures, ice melting, permafrost thawing, ocean acidification, increased precipitation, run-off and extreme weather events. ${ }^{7}$ As an example, POPs stored in sediment, soil or ice may be released to the environment, thereby increasing exposure to and potential uptake by organisms, resulting in elevated toxic effects. ${ }^{8}$ 
Through its working group the Arctic Monitoring and Assessment Program (AMAP), the Arctic Council (AC) plays an important role in synthesizing and communicating Arctic science to policy makers. ${ }^{9}$ For many years AMAP has had a specific focus on multiple stressors and other emerging environmental issues. While there has been an increase in the production of scientific knowledge on the integrated effects of climate change and hazardous chemicals, policy responses to address these challenges are few. ${ }^{10}$ Due to their transboundary character, these challenges require international collaboration and policy making. However, reaching international agreement on how to address a single environmental issue is demanding in itself and commonly takes many years to accomplish. Adding one or more stressors increases complications to such governance processes, partly due to the difficulties of communicating complex science on multiple stressor interactions. The scientific community often struggles to "prove" or reach consensus on the cause-effect relationships and provide evidence of adverse effects ${ }^{11}$ and then, summarize, translate and communicate these complex findings, with inherent uncertainties, to policy makers. Similarly, policy makers face challenges in transforming complex scientific findings into practical management measures and regulations. It is therefore important to improve the understanding of the interface between science and practical policy making in this area.

A guidance document ("the guidance") under the SC from 2015 is one of the few practical examples of international policies addressing multiple stressors (POPs and climate change). ${ }^{12}$ Using the 2009-2015 process of developing this guidance document as a case study, we analyze the organization of the science-policy interface and the role of AMAP in summarizing, translating and communicating scientific knowledge to the policy makers. We approach AMAP as an 'issue entrepreneur' and a 'boundary organization'; in which an issue entrepreneur is an actor that (re)raises issues through defining a problem, putting it on the agenda, connecting actors and expertise, and linking issues. ${ }^{13} \mathrm{~A}$ boundary organization may be defined as an institution operating in the "intersection of science and policy communities to broker or mediate interactions". ${ }^{14}$ Boundary organizations involve researchers, policy makers and professionals mediating between the former two; they are accountable to both sides; and they create 'boundary objects', such as assessment reports or models to facilitate communication. ${ }^{15} \mathrm{We}$ draw on a theoretical framework consisting of two core dimensions in science-policy interactions: separation (the relative distance between the realms of science and policy in a policy domain) and formalization (the procedures and practices of producing, synthesizing and communicating science for policymaking). ${ }^{16}$ More specifically, this paper analyzes the trajectory of AMAP as a boundary organization in navigating the landscape of formalization/separation in synthesizing, translating and communicating "Arctic" science on multiple stressors, and how this resulted in a policy guidance document under the SC. The study thereby contributes to the discussion on how complex science, including the degree and mode of co-production, influences global policy uptake. ${ }^{17}$ 
The first section provides a brief overview of the operation of the Arctic Council and how new chemicals are addressed by the Stockholm Convention on Persistent Organic Pollutants (POPs). The subsequent section outlines the theoretical science-policy framework and the methods applied to collect and analyze the data. The following fourth section presents the data and analysis, exploring the sciencepolicy trajectory on multiple stressors under the SC, before we in the fifth section draw some lessons and conclusions on how this study may contribute to improving the future international management of multiple stressors.

\section{The Arctic Council and the Stockholm Convention on POPs}

The Arctic Council (AC) is an intergovernmental forum promoting cooperation, coordination and interaction among Arctic states and other stakeholders, on common Arctic issues, including sustainable development and environmental protection in the Arctic. ${ }^{18}$ The forum consists of a) eight Arctic states, b) six Permanent Participants that are civil society organizations representing Arctic Indigenous peoples and c) observers from non-Arctic states and inter/non-governmental organizations. ${ }^{19}$ Since its inception in 1996 the AC has commissioned, produced, synthesized and communicated tremendous amounts of scientific knowledge on environmental challenges facing the Arctic. ${ }^{20}$ Among its six working groups, the Arctic Monitoring and Assessment Program (AMAP) is the most prominent group with regard to the production of scientific synthesis reports and environmental assessments. The main objective of AMAP is to monitor the Arctic environment and risks to Arctic ecosystems and human health, by synthesizing scientific research and local knowledge. Since the late 1990s, AMAP has carried out assessments on multiple environmental issues, including chemical pollution, climate change, ocean acidification and human health.

The involvement of AMAP in the development of scientific material varies depending on the assessment/report, but most commonly AMAP commissions work with scientists, organize the production of reports and review drafts. Sometimes the AMAP staff also act as co-authors. The assessment reports provide scientific support and advice to various stakeholders such as governments, civil society, inter-governmental institutions and scientists. The scientific knowledge provided by AMAP has been an important driver for policy and legislative actions on chemicals, both nationally and internationally. ${ }^{21}$

The Stockholm Convention on POPs (SC, effective from 2004) is a dynamic instrument, allowing new substances to be added by the initiative of any of its 183 Parties. ${ }^{22}$ To date, thirty substances have been regulated under the Convention, nominated by the EU, Norway, Mexico and Sweden. ${ }^{23}$ The process of nomination is cumbersome and resource demanding (Figure 1). ${ }^{24}$ In short, a country nominates a candidate chemical, including a justification for its listing based on scientific knowledge and assessments. The proposal is then considered against a set of criteria by a committee of experts in the Persistent Organic Pollutants Review Committee 

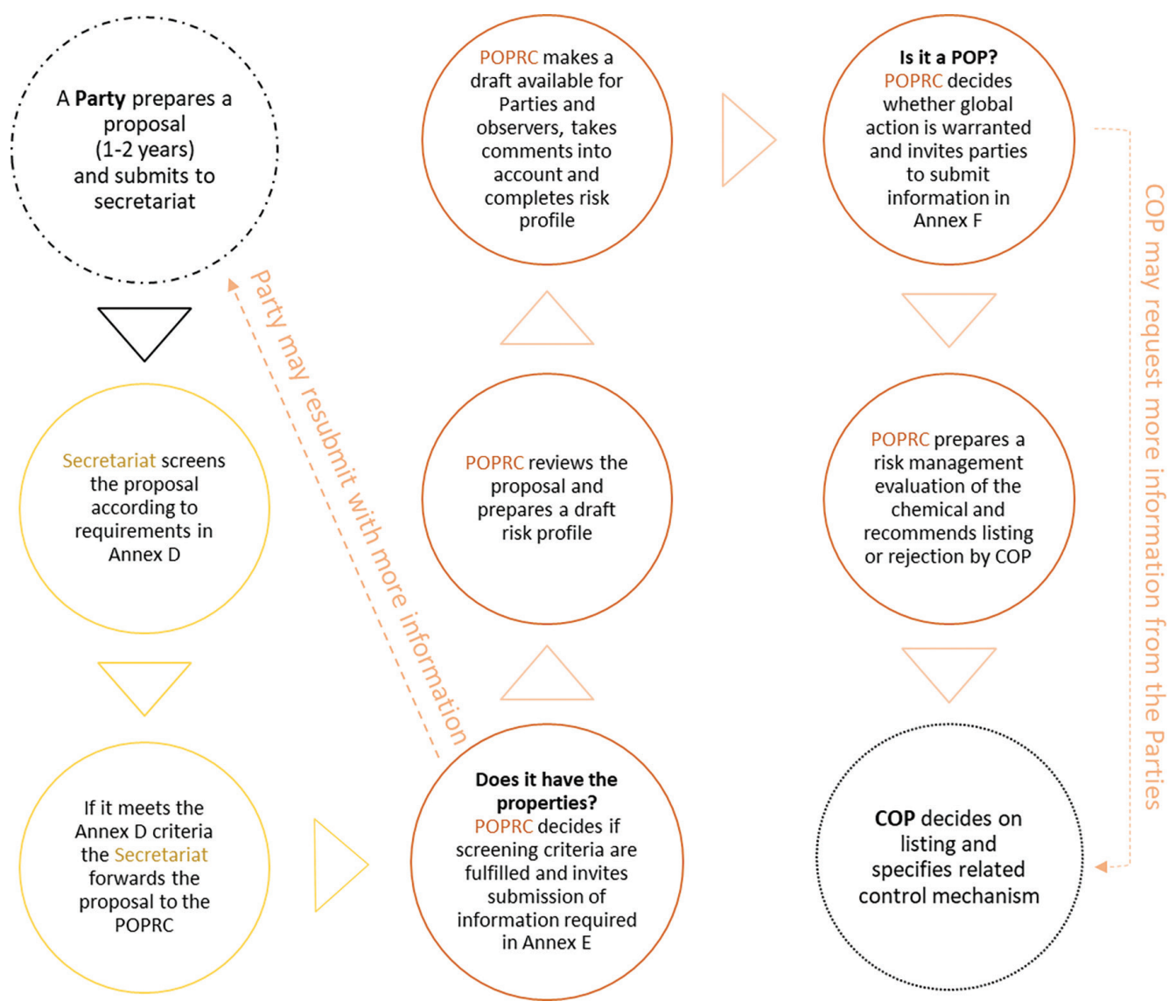

Figure 1. Nine-step process for nominating a new persistent organic pollutant (POPs) under the Stockholm Convention on POPs.

(POPRC) ${ }^{25}$ POPRC assesses the need for flexibility mechanisms and proposes listing or not to the Conference of the Parties (COP) of the Convention. Provided there is consensus in the COP, the chemical will be listed as a new POP. ${ }^{26}$

The average processing time from nomination to listing is four years. So far, most nominations have been granted, although for some, the process has taken up to ten years from nomination to the adoption of a complete ban. New POPs can be nominated by any Party to the convention but have historically only been nominated by four Parties.

The process of listing a new POP commences with the nominating party assessing and reporting extensive information on the sources of the chemical (production, use and release), its hazard potential, environmental fate-, monitoring- and exposure data, risk evaluations and regulations (Figure 1). The drafter is usually a representative from the nominating party. Based on the information provided in the proposal and information submitted in accordance with the Convention statutes ('Risk 
Profile'), the POPRC decides if the chemical is a POP. If so, the Committee will continue preparing a 'Risk Management Evaluation' (RME). In the RME process, Parties are invited to submit information on socio-economic dimensions, control measures, (chemical) alternatives, impacts on society, waste implications, access to information and public education, monitoring capacity and more.

The guidance document on climate change and POPs to be studied in the present report may be used as a basis for all steps of the nomination process. However, the RME, and partly the proposal step, are probably the most appropriate phases for addressing such interactions.

\section{Formalization and separation: key dimensions of the science-policy interface}

Theoretically informed empirical studies of the science-policy interface are important, both from a practical and scholarly point of view, as scientific knowledge plays a role in both the construction of and solutions to environmental issues. How to establish a fruitful interplay between science, other types of knowledge (e.g. local and tacit knowledge) and policy making has been widely debated in scholarly literature. ${ }^{27}$ Sundqvist et al. (2015) argue that science-for-policy arrangements can be studied along two basic dimensions: degree of formalization and degree of separation. ${ }^{28}$

Formalization concerns how knowledge should be synthesized for policy purposes, and by whom. These two questions are often labelled cognitive and social formalization, respectively. Some scholars are advocates for a high degree of social formalization, implying strict and formal selection procedures for assembling expert groups (e.g. "experts only" versus stakeholder involvement). ${ }^{29}$ Similarly, some argue that the procedures for selecting, synthesizing, and applying knowledge (cognitive formalization) should be as stringent and standardized as possible. Strong proponents for a high degree of formalization are often referred to as the evidence movement. At the other end of the formalization scale, we find the interpretive social sciences and constructivism arguing that science processes will always be influenced by individual judgments and contextual matters, no matter how formalized these processes are. ${ }^{30}$ These two strands, the evidence movement versus the emphasis on judgment and context bias can be thought of as opposite endpoints of a formalization continuum.

The second dimension, separation, concerns when and how science and policy should meet. At one end point of this dimension, we find those who argue that in order to prevent and avoid bias in expert knowledge, scientists should be separated from the domain of policymaking and public administration until expert consensus has been reached; only then should science connect to policy. ${ }^{31}$ This position is often referred to as speaking truth to power. Critics of this perspective argue that science and policy, facts and values, are inextricably intertwined in a fluid and constantly interchanging relationship, i.e. co-produced..$^{32}$ According to this view, instead of artificially attempting to separate science and policy, we should rather find clever ways 
of integrating science and policy, by empirically investigating and de-constructing translation processes ${ }^{33}$ and studying modes of co-production. ${ }^{34}$ This includes studying how different actors and organizations perform boundary work, that is, how and where to draw the boundaries between science and non-science, ${ }^{35}$ as well as the boundaries between science and policy. ${ }^{36}$ The stances of speaking truth to power versus co-production and boundary work, can be referred to as opposite endpoints on a continuum called separation. ${ }^{37}$ Boundary organizations, i.e. organizations operating at the science-policy interface (of which AMAP is an example), will always have to navigate along the dimensions of formalization and separation. ${ }^{38}$ These two dimensions, formalization and separation, constitute the theoretical framework for our analysis. We will study how AMAP as a boundary organization navigates and operates within these two dimensions, and the corresponding policy outcome under the SC.

Constructivism, from which the formalization/separation framework is inspired, encourages empirical studies of the construction of objects, in our case, an international environmental governance regime on multiple stressors. Applying this framework, one can study how and why an environmental problem is first constructed, how it evolves over time, and how it is re-constructed. In our case study, we find that the two stressors climate change and hazardous chemicals were initially defined and governed as separate environmental issues, whilst later they were addressed by scientists as interlinked. This process created new, re-framed environmental problems, which over time altered the way that the "original" environmental problem was defined, studied and governed. So far, there are few studies of such environmental policy making trajectories, or issue linking, based on the formalization/separation framework. ${ }^{39}$

By examining multiple stressors (interaction of climate change and POPs) as a case study, in its analysis of the construction and re-construction of an environmental issue as "an object", this paper aims to empirically elucidate the role of AMAP as an agenda setter and boundary organization. We also aim to advance the discussion on how boundary organizations navigate the key dimensions of separation and formalization in seeking to develop and fulfil their mandate. The case study approach is motivated by the exploratory nature of this research. As to date, little has been written about the process of integrating science on multiple stressors into international policy. Following Gerring's (2004) definition of a case study as 'an intensive study of a single unit for the purpose of understanding a larger class of (similar) units', we argue that our case has relevance to similar environmental policy processes. ${ }^{40}$

\subsection{Methods and data collection}

In our data collection we have focused primarily on the time period from 2009 to 2015 to capture the most critical events leading up to the development of a multiple stressor policy document. However, for the review of AMAP's work on multiple stressors, we have used a broader time range, from 1997-2019. The main 
methodology used in the paper is document analysis of AMAP and UNEP assessment reports, strategy documents, work plans, policy drafts, meeting reports/minutes, Earth Negotiations Bulletin (ENB) reports and summaries, and nomination documents of new POPs to the SC. We have analysed 36 AMAP assessment reports from 1997 to 2019 (see Table 1) and categorized these according to the degree to which they link and address the coupling of climate change and chemicals. ${ }^{41}$ Degree of attention was categorized as: limited (briefly touched upon the issue), considerable (several references to scientific literature and/or segments of text specifically addressing the issue) and entirely (reports that deal in their entirety with multiple stressors or that contain an entire chapter on the issue).

We also analysed six nominations of candidate POPs between 2011 and 2019 to determine if these contained any reference to climate risk, the AMAP/UNEP report and/or the SC guidance document. ${ }^{42}$ Although a detailed assessment of the influence of the policy is beyond the scope of this study, our analysis provided us with an overview of the application of the key documents on multiple stressors to date.

We further conducted four key informant interviews ${ }^{43}$ with senior officials at the Norwegian Environment Agency and the Swedish Chemicals Agency, as well as with current and former employees at AMAP. The interviews were loosely structured and two were conducted in an informal manner. The informants have participated in and hold in-depth knowledge about several steps of the process of co-producing and developing the guidance document. The first author of the paper has a professional background as a delegate to multilateral environmental agreements, to AC expert groups and as a reviewer. His experience and networks facilitated the identification of informants, informal discussions, and helped to define the scope of the study.

\section{The process of translating science into policy}

The process of translating Arctic science ${ }^{44}$ into global policy on multiple stressors was complicated and involved several stages. We have categorized the process into five chronological, but partly overlapping steps: 1) Building the body of scientific evidence (1997-2010), 2) Boundary work and co-production of a report on multiple stressors (2009-2011), 3) Policy drafting and negotiation (2011-2013), 4) New framing - from "guidance" to "approach" (2012-2015), 5) Assessing the policy outcome and impact (2015-2019). An underlying assumption for the study has been that AMAP is a relatively independent science provider. However, as a body under the AC and steered by the AC member states, we will start by investigating the AMAP steering principles and degree of scientific autonomy.

\subsection{Building the body of scientific evidence (Step 1)}

AMAP was an early mover in linking climate change and environmental pollutants, already covering the topic in its first comprehensive report on Arctic pollution issues in 1997/1998 (Table 1). In this report climate change was mentioned as one of several 
Eirik Hovland Steindal et al.

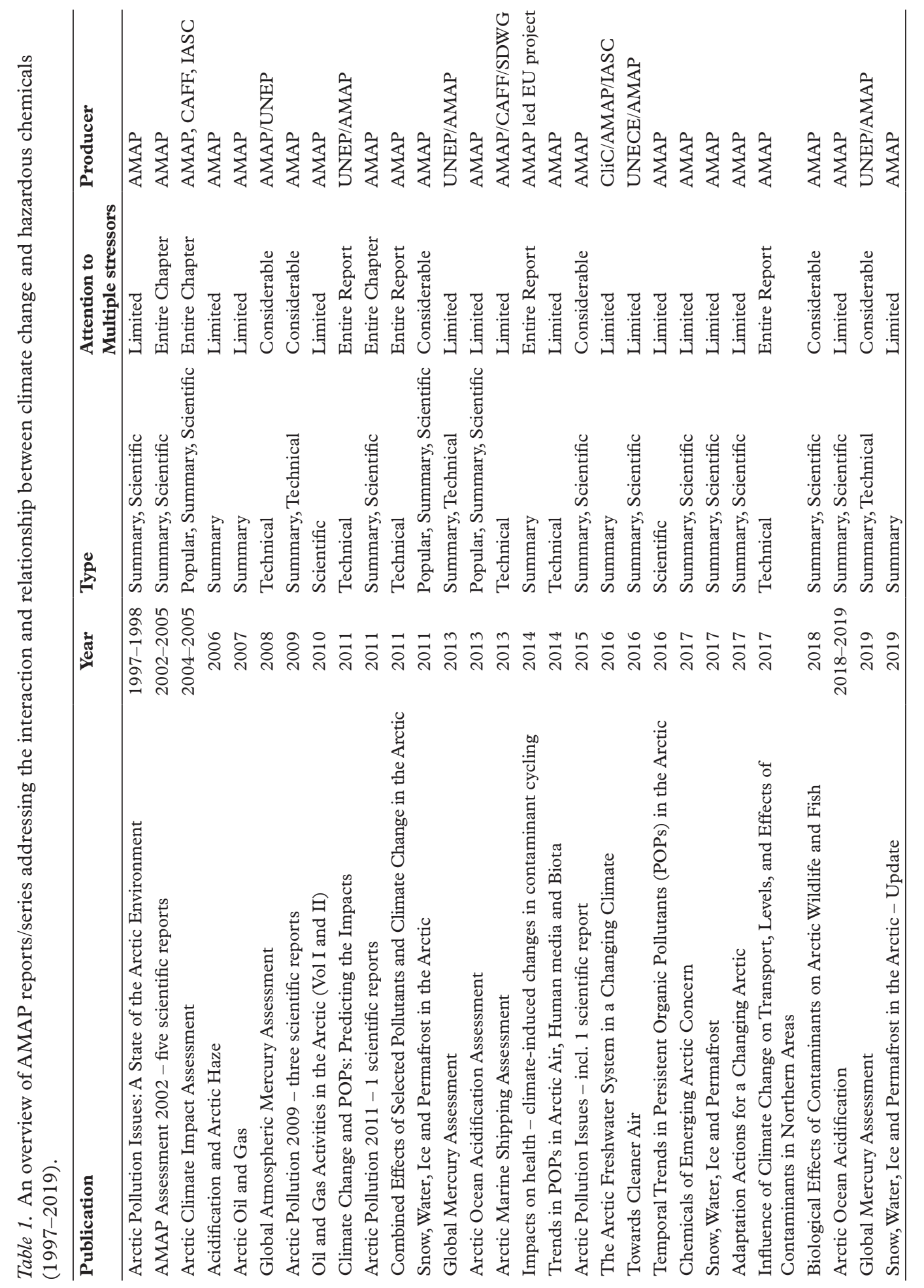


stressors "not directly related to chemical contamination", but that could impact the effects of environmental pollutants "since the stressors may affect their [species/ecosystems] health in a variety of ways". ${ }^{45}$ The report made an explicit call for more scientific knowledge about the issue. The AC responded with a mandate from its coordinating body, the Senior Arctic Officials (SAO), through the Ministerial declarations. In 1997, during a meeting in Alta, Norway, the participating ministers encouraged further work from AMAP and put a special emphasis on multiple stressors. ${ }^{46}$ The directive was followed up the next year with the adoption of the AMAP workplan for the period 1998-2003. Hence, AMAP's increasing focus on multiple stressors during this period (Table 1) not only reflected a growing body of scientific literature on the topic, but also a more explicit mandate. On the one hand this illustrates the relatively independent (i.e. separate) role of AMAP. On the other hand, it signals that there is an actual interface in different phases of the process, and that the AC sends signals to which AMAP responds and vice versa (co-production). However, little is revealed regarding formalization, which may indicate an extensive scope for expert judgment and low degree of formalization, as formalizing procedures are usually explicitly described.

AMAP responded to the call for more scientific knowledge on multiple stressors in its subsequent assessment report from 2002. The report included five scientific sub-reports and a more explicit focus on multiple stressors. With one of the five sub-reports specifically addressing interactions between climate change and contaminants, AMAP again called for more research on how contaminant transport and fate may be influenced by climate change. ${ }^{47}$ In the accompanying policy recommendations, commissioned by the Arctic Council, authored by the scientists and the AMAP secretariat, and lastly adopted by the AMAP Working Group (i.e. indicating low separation), AMAP was encouraged to carry out further investigations on climate change and POPs interlinkages and effects, to "enable Arctic States to better undertake strategic planning when considering the potential effectiveness of present and possible future national, regional, and global actions concerning contaminants". ${ }^{48}$ This, and the fact that that the report contained (prescriptive) policy recommendations, suggests a low degree of separation at this stage. The recommendation was built on scientific evidence in the report stating that the fate and route of transport to the Arctic was "strongly influenced by climate variability and global climate change". ${ }^{9}$

\subsubsection{Why did AMAP address multiple stressors?}

Importantly, the direction of influence between science and policy has not been a oneway route. It is not uncommon that the AMAP secretariat contributes significantly with input to the drafting of SAO mandates, strategies and working plans..$^{50}$ The secretariat therefore had influence on its own mandate and steering documents. In our review of the AMAP assessments, several reports contained an encouragement or recommendation to ask AMAP to carry out further work on issues related to multiple stressors. ${ }^{51}$ Hence, these organizational and operative dynamics, in combination with previous analyses of AMAP's independent role ${ }^{52}$, suggest that AMAP was operating rather autonomously 
in pushing multiple stressors on the agenda, though still keeping an eye on policy. Our analysis suggests that AMAP is best understood as a boundary organization with an arm's length distance to both science and policy. In other words, in the first phase of this policy process, AMAP operated with high degree of separation. The organization of the assessment and review process adds support to these assertions.

\subsubsection{Review process - organization of assessment process}

The AMAP reports were authored and reviewed by scientists from a range of disciplines (Table 1). AMAP has also established a formal procedure for a wider review of its reports, and the review process contributes to shedding light on both the degree of formalization and the degree of separation. ${ }^{53}$ The development of a report is carried out by an expert group (EG). The experts are nominated by member states, permanent participants, observer countries and other organizations. An EG is led by two co-leads appointed by AMAP, normally from countries identified as "AMAP lead countries". AMAP strives to achieve balance with regard to both geography and gender. Besides being involved in the nomination and selection of experts to develop assessment reports, AMAP is responsible for appointing peer-reviewers. As part of this, the AMAP WG may instruct its own secretariat to draft specific parts of the scientific assessment reports. Although such a close link to the member states would suggest a low degree of separation, this is counterbalanced by a high degree of social formalization in the selection of experts and what roles the experts shall have. It is, for instance, explicitly stated in the procedure that the experts represented in the EG shall be independent "individuals acting in their capacity as scientists or experts in specific fields, and not representing the views of any country or organization". ${ }^{54}$ The selected experts have considerable independence in how they assess, select and author scientific knowledge, suggesting a low degree of cognitive formalization.

\subsubsection{Separation and formalization in building the evidence base}

Our analysis shows that from 1997 to 2020 the climate change-POPs interlinkage is addressed in the vast majority of AMAP reports, with several exclusively dedicated to the issue (Table 1). This confirms AMAP's position as a prominent agenda setter and boundary organization for emerging environmental issues. ${ }^{55}$ Many of its assessments on emerging environmental issues go far beyond the policy focus of the AC-member states. In line with previous research, ${ }^{56}$ we find that AMAP has been pivotal in building the body of evidence by recurrently synthesizing science and thereby repeatedly bringing multiple stressors to the attention of policy makers.

Furthermore, we show how AMAP has strived to keep policy makers at arm's length distance and protected its scientific autonomy through a high degree of social formalization (i.e. the selection of experts and reviewers, and how their roles and mandates have been regulated), combined with a low degree of cognitive formalization (i.e. limited control and regulation of how knowledge is collected and assessed). Our results also demonstrate that AMAP has addressed multiple stressors for many 
years without involving decision making bodies at various governance levels. This indicates a high degree of separation. The tenacity and persistent effort to compile and assess scientific knowledge on multiple stressors, combined with highly social formalized work at an arm's length distance to policy makers, seems to have contributed to AMAP's status as a credible, relevant and legitimate issue entrepreneur within international policy making.

\subsection{Boundary work and co-production of the report on multiple stressors (Step 2)}

The first global monitoring plan of the SC in 2009 recognized the relevance of climate and POPs interlinkages (Figure 2). ${ }^{57}$ In particular, it raised the importance of taking climate effects into account when assessing temporal trend data on POPs. As a consequence, the fourth COP of the SC in 2009 requested its monitoring coordination body to: "assess climate influences on the levels of POPs measured in the environment and in humans and the relevance for how these influences may interfere with present and future evaluations of the effectiveness of the measures undertaken through the Stockholm Convention" ${ }^{58}$ The mandate was pioneering in the sense that a single-issue regime expressed a clear focus on the potential influence and interplay of multiple stressors.

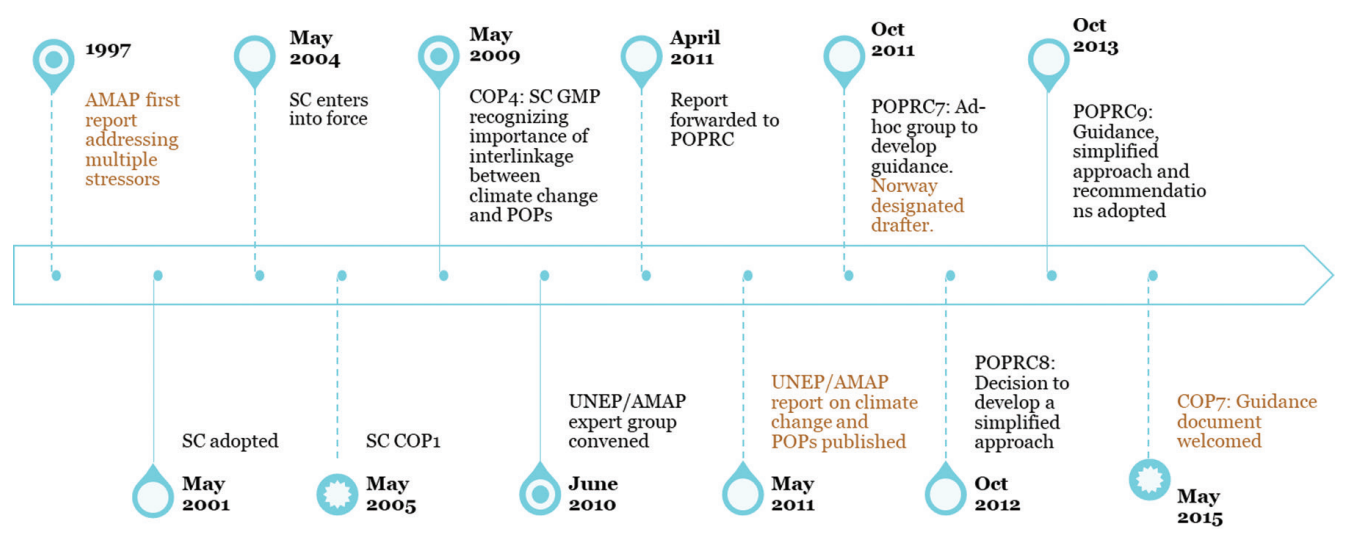

SC-Stockholm Convention on POPS

GMP-Global Monitoring Plan under the SC

POPRC-Persistent Organic Pollutant Review Committee

AMAP-Arctic Monitoring and Assessment Programme

UNEP-UN Environment

COP-Conference of the Parties

Figure 2. Timeline of Arctic science translation into policy under the Stockholm Convention on POPs.

\subsubsection{Deciding on co-production}

Responsibility for the assessment was appointed to a dedicated expert group by the SC secretariat and AMAP. It convened in 2010 under their leadership. The move displayed a transition to co-production, a high degree of social formalization and low separation. AMAP had a strong presence at this meeting with three key 
members from its secretariat, including the executive secretary. ${ }^{59}$ Two years earlier the two institutions had co-produced an assessment report on mercury, a report preceding negotiations on a global instrument on mercury, the Minamata Convention (Table 1). From the late 1990s and into the early 2000s, AMAP increasingly interacted with the processes that led to the 2001 adoption of the SC (Figure 2). AMAP was also active in the years thereafter in supporting ratification and implementation of the Convention. ${ }^{60}$ The importance of strengthening the science-policy nexus through enhanced co-production and "collaborative assessment processes" was emphasized by both AMAP and the SC. ${ }^{61}$

The expert group (EG) consisted of a mix of experts associated with both UNEP and AMAP, as well as non-affiliated scientists and non-governmental organization (NGO) representatives. By reaching out to their network of scientists with a long track-record of working in the Arctic, AMAP ensured that the work was linked to Arctic science. For AMAP the co-production with UNEP expanded both the scope of the report and its reach from the Arctic region to the global level. The result of this work was the report Climate Change and POPs: Predicting the Impacts published in 2011.62 The report included an updated scientific assessment as well as a set of policy recommendations.

\subsubsection{Co-production: low degrees of formalization and separation}

The process leading up to the 2011 report illustrates that AMAP's boundary work had influence the decision to co-produce a report, by its strong presence at the COP, by offering to do (part of) the work and through its well-established history of collaboration and previous experience of co-production with UNEP. The group of authors, contributors and reviewers included representatives from UNEP, AMAP, NGOs, free-standing scientists and government officials, which reflects a low degree of separation and a high degree of co-production. Examples of AMAP's active boundary work under the SC has also been discussed elsewhere, linking the nominations of new POPs to the policy recommendations promoted in AMAP assessment reports. ${ }^{63}$ However, pointing in the direction of a high degree of separation, the final AMAP/ UNEP report was communicated as a (descriptive) scientific product. Furthermore, it was emphasized that the report did not necessarily reflect the views of either UNEP or AMAP. On the other hand, the prescriptive policy recommendations of the report were not written by scientists but by one representative from UNEP and one from an environmental NGO, indicating a low degree of separation. Taken together, this information illustrates attempts to formalize and mask a process with a low degree of separation to strengthen the credibility, legitimacy and relevance of the report.

\subsubsection{The uncertain fate of the report}

So how was the report received? The draft decision presented to the fifth COP for further deliberation was limited to "taking note of the report" and "to encourage 
Parties in a position to do so to support further studies to fill regional and thematic data gaps". ${ }^{64}$ According to our informants, several Parties in the meeting expressed concern about coupling the two issues, including the Chair of the COP, who opposed further action based on the report. ${ }^{65}$ One informant stated:

\begin{abstract}
When we first brought it up, it was a bit early. I remember that one prominent party was very skeptical. Some delegates thought that we were opening Pandora's Box since climate change can alter POPs in several ways, both positive by reducing the problem [e.g. faster degradation] and negative [e.g. enhancing the range and fate]. There was resistance from both sides. ${ }^{66}$
\end{abstract}

Others were afraid that coupling climate change with chemicals could contribute to diverting attention to other competing issues and thereby cause a dislocation of funds from chemicals to issues such as biodiversity and climate change. AMAP was also present at this meeting with two of its key staff, including its Executive Secretary. ${ }^{67}$ The strong skepticism expressed by some Parties towards the report, could have resulted in the report being "shelved", but as we will see, some actors wanted it otherwise.

\title{
4.3 Policy drafting and negotiations (Step 3)
}

Whereas the draft decision proposed that the COP should only take note of the report, views diverged on what to do next. In the midst of this confusion, the Norwegian delegation suggested that the POPRC should be given the task of assessing how climate change interactions could be accounted for in the potential listing of a new POPs under the SC. Supported by the EU and an NGO (and possibly others), Norway managed to push through a decision to forward the report to the POPRC with a request to "consider the possible implications of those interlinkages for the Committee's work". ${ }^{68}$

\subsubsection{Norway decides to take a role}

Norway's active role in promoting the multiple stressor issue may partly be explained by its general interest in Arctic environmental issues. ${ }^{69}$ As an Arctic country, Norway is committed to detecting risks affecting the region, including the likely long-range transportation of POPs. Norway has monitored pollution in the Arctic for many years, and has therefore put significant emphasis on communicating and promoting Arctic field data. ${ }^{70}$ One key Norwegian official explained that with rising acknowledgement of the POPs and climate change interlinkage in the Arctic, it has become clearer that this is also a problem in other parts of the world. ${ }^{71}$ Yet, our analysis shows that transformation of the 2011 report into specific policy was not something the Norwegian delegation had prepared for. Rather, this materialized and was decided upon at the meeting, partly driven by individually engaged bureaucrats and NGO observers acting as policy entrepreneurs. ${ }^{72}$ 
Once the discussions commenced in the following POPRC meeting (Figure 2), it was decided that a guidance document for the Convention should be developed. The purpose was to guide Parties in how to assess the potential added risk of climate change when evaluating a new POP. One of the Norwegian bureaucrats volunteered as a drafter. This was a strategic move that turned out to be pivotal for the establishment of an ad-hoc working group that would develop "the guidance" in 2011. A guidance document is commonly a non-binding informational document that provides key guidance to the Parties related to the implementation of a regime. Even though such guidance documents are not obligatory, they may be fiercely discussed and opposed by Parties that are concerned with such changes potentially establishing precedence or indirectly modifying the regime (either by becoming more stringent or more lax).

\subsubsection{AMAP and science is set aside}

At this point in the process, with Norway taking a leading role, the role of AMAP was gradually fading out, again separating science and policy. AMAP did not have the same presence and participation at the POPRC meetings as it had had in the COP meetings. ${ }^{73}$ However, the strong presence of AMAP early on in the process, the firm ownership of Norway and its close alignment with AMAP and Arctic monitoring data, may help to explain why it was specifically stated that the working group should use the 2011 UNEP/AMAP report as the basis for its work. ${ }^{74}$ Yet, when discussions on concrete policy action started to heat up, neither AMAP nor science were in the front seat of the discussions any longer.

\subsection{New framing - from "guidance" to "approach" (Step 4)}

Preparing a guidance document under POPRC turned out to be a long and winding road, as several concerns related to integrating climate change and POPs emerged during the process. One informant stated that climate skepticism was more commonplace among the negotiators in the early $2010 \mathrm{~s}^{75}$ The amount of empirical data on climate change and POPs interactions was increasing but still limited, complicating the integration of climate change data and IPCC reports in POPRC's work. ${ }^{76}$ The US was particularly hesitant to mix the two issues. ${ }^{77} \mathrm{An}$ interesting aspect in this context was the use of the word "predicting" in the title of the AMAP/UNEP 2011 report. This word indicates a lack of data, which according to one informant, may have reduced the weight of the report, adding to the reluctance among certain actors to couple these stressors under the SC..$^{78}$

\subsection{1 "The guidance" and "the approach" - new policy framing}

In spite of these concerns, there was a good collaborative spirit within the ad-hoc working group, and the group was able to work without much critical intervention. ${ }^{79}$ Between 2011 and 2015, the POPRC working group developed several drafts of "the 
guidance" document and presented drafts at three consecutive meetings (POPRC7-9). Progress updates were shared with the COP. The resulting 57-page guidance document closely resembles the UNEP/AMAP report from 2011. The document "highlight [s] interactions between POPs and climate change that are relevant to the review processes of new POPs in POPRC". ${ }^{80}$ The close similarity between the 66-page AMAP/UNEP report and "the guidance", suggests that the latter to some extent is a new policy framing of the former. ${ }^{81}$ For instance, "the guidance" document applies the same conceptual framework for indicating connections between stressors. ${ }^{82}$ In addition, parts of the preface to "the guidance" is identical in wording to parts of the preface of the UNEP/AMAP 2011 report. Moreover, "the guidance contains" 113 references to the UNEP/AMAP report, including numerous references to its policy recommendations.

Nevertheless, the shaping of the policy document was influenced by the initial concerns raised, and it was decided to make a more "simplified and practical", stepby-step approach. ${ }^{83}$ The ad-hoc working group was therefore instructed to make a shorter guidance document ("the approach") partly because the COP supposedly could not deal with a long document. ${ }^{84}$ However, this was also a strategy to reduce the sensitivity of "the guidance". 85 "The approach" briefly presents a methodology for climate change impacts and interactions with POPs under review. Hence, at its ninth meeting the POPRC adopted three different texts: 1) "The guidance" - the original guidance document on how to assess the possible impact of climate change on the work of POPRC, 2) "the (simplified) approach" to a consideration of climate change interactions with the chemicals proposed for listing in Annexes A, B and/or C of the SC, and 3) a set of science-based policy recommendations developed on the basis of "the guidance", "the approach" and the UNEP/AMAP report. ${ }^{86}$ At the same meeting it was decided that the Committee would use both "the guidance" and "the approach" for "future evaluation of chemicals proposed for listing" ${ }^{87}$ These policy developments may be characterized as a way of "doing politics by other means" by formalizing the procedures to follow in order to link climate change and POPs, indicating that formalization may also be used to complicate and thus ease sensitive and disputable matters. ${ }^{88}$ It seems evident that the issue was considered politically sensitive, and for various reasons, Parties were reluctant to integrate another stressor (and thereby lean more heavily towards the precautionary principle.) ${ }^{89}$ Apparently, these factors contributed to the formalization of the procedure.

\subsubsection{Watering down the role of science}

The process of condensing the 57-page guidance document to a 9-page approach was highly political. ${ }^{90}$ During the negotiation phase, the formulation of guidance documents is often controversial and heatedly discussed by the parties involved, who may fear that the adopted documents will become the norm for interpretation and/or implementation. Such was the case here. Some Parties were concerned 
that "the guidance" would establish precedence, triggering the development of more binding rules in the future, more frequent nominations of chemicals and/or more expensive reduction measures. Porter (1995) argues that organizations under pressure as a result of decreasing separation between science and policy may respond with increasing formalization. ${ }^{91}$ New guidance complicating processes could be an example of such formalization.

It is not uncommon that a policy document differs from a scientific assessment report. However, the push to transform "the guidance" into a shorter and more accessible approach and 'recommendation', introduced the risk of watering down both the scientific basis (provided in the assessment report) and the stringent (i.e. formalistic) full format guidance document. One example highlighted by one of our informants was that in "the approach" the scope of "the guidance" was reduced to an assessment of the climate risk of individual substances, i.e. not groups of substances, setting an elevated threshold for evaluating climate change and POPs interactions. Demanding proof may also be considered a type of formalization: by reducing the scope of "the guidance", the opponents performed politics by other means. The precautionary principle is actively used in the SC, although there is significant discussion as to what the precautionary principle legally implies. ${ }^{92}$ Some countries, such as the Nordic countries and the EU, put more emphasis on inherent chemical hazard characteristics, whilst others to a larger extent use risk assessments as a basis for the regulation of chemicals (e.g. North America). ${ }^{93,94}$ This difference in regulating and managing chemicals also reflects a difference in the interpretation and application of the precautionary principle and thus helps to explain some of the reluctance encountered when introducing climate change considerations and why some Parties sought to limit the scope of the policy process.

Despite the resistance, why was "the guidance" accepted under the SC? Various factors can help explain the inclusion of an "emerging issue" as an additional stressor under the SC: 1) it was a non-binding guidance document and few Parties were concerned about the implications of implementation; 2) the scientific basis had been developed over a long period of time and frequently compiled by AMAP; and 3) the development of the scientific assessment had been requested by the SC itself, and the policy makers were aligned with the process, kept updated on the progress and negotiated the policy recommendations in the report; and 4) a predominant share of the nominations had so far been submitted by EU and Norway, putting the burden of proof, in terms of time and resource demand, partly on the nominating Party or the Parties drafting the various documents for POPRC/COP consideration. Lastly, and possibly most importantly, 5) the SC had a scientific evaluation committee, POPRC, comprised of nominated government experts. The Committee was known to carry out rigorous and highly technical evaluations of new, nominated chemicals. Thus, the experience and history of such evaluations had established a certain level of trust in the processing of scientific data and assessing its credibility. 


\subsubsection{Oscillation within the continuum of formalization and separation}

Drawing on Sundqvist et al. (2015), our analysis shows that the way in which a boundary organization operates on the continuum of separation between science and policy is not static but may fluctuate throughout a policy process (Figure 3). AMAP was working on multiple stressors without policy involvement for more than a decade (Step 1). Parallel to being an Arctic forum mandated by its member states, AMAP has established highly formalized procedures for synthesizing scientific data, manifesting its scientific autonomy and credibility. Fourteen years after its first report on the issue, and in line with its strategies to support policy, AMAP entered into co-production of a report with UNEP (Step 2). This was a move to enhance the impact of its boundary work, on a transboundary issue that clearly warranted international cooperation and solutions. Doing so, AMAP had to adapt to accommodate a more heterogenous group of participants, including intergovernmental organizations (IGOs), NGOs, scientists, and policy makers. Our analysis suggests that this process was scientifically and politically more muddled than in situations where AMAP worked independently. Yet, UNEP ensured that the political process, the organization of the expert group and its interlinkage with the COP followed the regular Convention procedures. Subsequently, after POPRC was given the task to see how the coupling of climate change and POPs should be integrated in its work (Step 3), the role of AMAP and scientific evidence were scaled down. Nevertheless, Norway's close affiliation with AMAP and Arctic monitoring data, helped ensure that "the guidance" was closely aligned with the AMAP/UNEP report. Once the draft guidance materialized, policy negotiations intensified and contributed to reframing the document (Step 4), distancing it further from its scientific starting point in the AMAP/UNEP report. Science and policy were again separated. In parallel, the fouryear-long interaction between the POPRC drafting group, the POPRC and the COP, was becoming highly charged and political.

\section{AMAP (decreasing) influence / involvement}
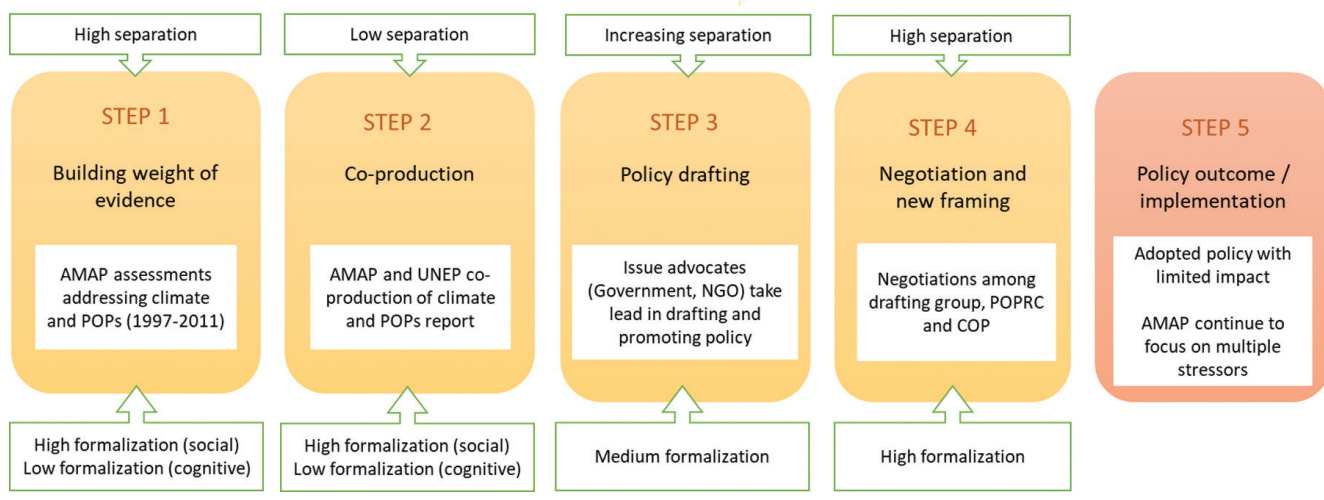

Figure 3. Trajectory of transforming science on climate change and POPs interactions into policy under the Stockholm Convention. 
To summarize, it seems clear that AMAP's initial strategy of a high degree of separation helped to link climate change and POPs and put the issue on the political agenda. When tasked with co-producing a report with UNEP, this led to less separation, but extended AMAP's influence as a boundary organization. The decision to transform the report into policy should be seen as an achievement for AMAP, considering that few countries had addressed multiple stressors in their respective national policies. The political process and negotiations that followed in the next round led to increased separation when "the guidance" and "the approach" were to be produced, largely leaving AMAP on the sideline. Put differently, a high degree of separation may in the next round lead to a low degree of separation, and vice versa. This fluctuation must also be seen in relation to different degrees of formalization. Whereas AMAP had developed highly socially formalized procedures for carrying out assessments, combined with low cognitive formalization, leaving a high degree of expert judgement, these procedures were simplified when entering co-production with UNEP. This step involved a broader selection of contributors and authors, and a combination of AMAP procedures for scientific assessment processes and UNEP procedures for hiring consultants as knowledge providers. Nonetheless, once "the guidance" was approaching finalization, the process was less about science, and more about policy wrapping.

\subsection{Assessing the policy outcome and impact (Step 5)}

Only a handful of chemicals have been nominated since the AMAP/UNEP report in 2011, and even fewer since the COP welcomed the guidance document in 2015 (Table 2).

Table 2. Nominations of candidate POPs $(n=6)$ between 2011 and 2019, incl. references to climate change, the AMAP/UNEP 2011 report and SC guidance on climate change and POPs.

\begin{tabular}{|c|c|c|c|c|c|}
\hline \multirow[b]{2}{*}{ Chemical } & \multirow[b]{2}{*}{$\begin{array}{c}\text { Proposal } \\
\text { year }\end{array}$} & \multirow[b]{2}{*}{ Proposer } & \multicolumn{3}{|c|}{ Reference to: } \\
\hline & & & $\begin{array}{l}\text { Scientific } \\
\text { literature }\end{array}$ & $\begin{array}{c}\text { AMAP/UNEP } \\
\text { report }\end{array}$ & $\begin{array}{c}\text { "The } \\
\text { Guidance" }\end{array}$ \\
\hline Dechlorane Plus ${ }^{\star}$ & 2019 & Norway & No & No & No \\
\hline Metoxychlor ${ }^{\star}$ & 2019 & EU & No & No & No \\
\hline $\mathrm{PFHxS}^{\star \star}$ & 2017 & Norway & Yes (one study) & No & No \\
\hline PFOA & 2015 & EU & Yes (one study) & No & No \\
\hline Dicofol & 2014 & EU & No & No & No \\
\hline DecaBDE & 2013 & Norway & Yes & Yes & Yes (draft) \\
\hline
\end{tabular}

^Dechlorane Plus and Metoxychlor were nominated in 2019 and have only come to the screening process (Figure 1). Only the proposal and screening documents were assessed. Most commonly such information would be added in the Risk Profile phase.

$\star \star$ POPRC has recommended listing of PFHxS with no exemptions, thus the substance is likely to be listed in 2021. 
Screening the documents submitted for the different steps of nomination (Figure 1) of the six candidate POPs nominated since 2011, we found a limited number of references to multiple stressors (Table 2).

In fact, both the AMAP/UNEP report and "the guidance" have so far only been incorporated in one of six nominations. Notably, this was the nomination of DecaBDE, initiated by Norway in 2013, two years after the AMAP/UNEP report was published and while "the guidance" was still being drafted. Norway's proximity to the two processes, its nomination of DecaBDE and its role as drafter of "the guidance", is a likely explanation as to why these documents were integrated into the nomination process at this specific point.

Since then, no other references have been made to the two core documents on multiple stressors: the AMAP/UNEP report and "the guidance". The only Parties that have nominated candidate POPs during this period are Norway and the EU, the policy's most explicit promoters among the SC Parties. Our informants stated that the process of nomination is already extremely demanding, which can partly explain why science on multiple stressors and "the guidance" play a marginal role in assessing new POPs. ${ }^{95}$ There is generally substantial opposition from countries and industry to any new listing of chemicals. Many countries argue against the restriction or alternatively argue for various exemptions that potentially may contribute to undermine the regulation. There is limited capacity or need to add additional scientific knowledge to the human and environmental risk of climate change and POPs interactions. That said, all Parties and POPRC members have the chance to integrate multiple stressor perspectives into the evaluation process. Given the fact that only Norway and the EU have nominated chemicals over the last fifteen years, at present it seems unlikely that any other party will take the lead to couple climate change and hazardous chemicals under the SC.

\section{Conclusion}

In this paper we have analyzed how science on multiple stressors was translated into international policy under the SC. Applying the separation-formalization framework, we have explored the different roles and trajectory of AMAP as a boundary organization navigating the science-policy nexus of climate change and POPs. AMAP's role in orchestrating the interplay between scientists and policy makers contributed to enhancing the scientific foundation for policy-making and in translating science into concrete policy.

As a boundary organization, AMAP has played a pivotal role in setting various emerging environmental issues on the political agenda. Focusing on the Arctic and Arctic science, AMAP has increasingly scaled up to the broader international arena, through enhancing its collaboration with UNEP. We conclude that this was also the case in the coupling of climate change and hazardous chemicals, where AMAP was a highly successful issue entrepreneur. Our analysis suggests that AMAP's practical 
reflexivity of the dimensions of formalization and separation has allowed it to maneuver in unchartered territories, fulfilling its mandate on multiple stressors and putting knowledge into action in the form of a guidance document.

Rather than taking a static position regarding separation and formalization, our case study has demonstrated how AMAP has reflexively and consciously navigated the landscape of separation and formalization in an oscillating manner. We find a rather high degree of separation and formalization during a period of almost fifteen years when AMAP autonomously compiled and promoted the increasing body of science. From this we see a move to a low degree of separation and formalization to enhance policy impact when entering co-production with UNEP. Lastly, AMAP was separated from policy decisions when the policy discussions heated up and negotiation procedures under the Convention became formalized in terms of social formalization, in a lengthy process that included only country delegates and registered observers to the POPRC/SC.

The formalization/separation framework has proven useful as a framework to understand the workings of boundary organizations navigating and operating from different positions in the landscape made up of these two dimensions. A high degree of separation may contribute to establishing credibility for a science provider, though possibly at the expense of policy relevance and feasibility. However, shifting to a co-production mode and a low degree of separation may on the contrary have the benefit of increasing relevance, salience and thus the probability of policy influence. Moreover, the results highlight the advantage of "cascading effects", implying that the work of a boundary organization alone is not enough to ensure the transition of science into policy. Rather, a group of likeminded actors, with similar interests may be pivotal for such a transition. That said, as the process moved closer to the policy framing, it was evident that once the process was materializing and coming closer to a potential policy impact, bureaucrats took the lead, watered it down and ensured that the outcome was politically acceptable, albeit less in line with the science. Nevertheless, it is unlikely that the process of constructing a science-based governance regime for multiple stressors would have come that far had it not been for AMAP's skillful navigation as a boundary organization and issue entrepreneur. Consequently, this case study suggests that the ability of a boundary organization to oscillate between high and low degrees of formalization and separation is a necessary but insufficient condition for a boundary organization to achieve policy impact.

On the subject of environmental governance, this case study has brought forward important knowledge regarding the challenges of issue-linking and addressing several stressors under a single-stressor regime. In general, the system was inadequately prepared to address multiple stressors, as illustrated by: 1) competition between regimes regarding funding allocations; attention to this triggered a reluctance for coupling the issues, 2) some countries were not Parties to all of the regimes, and concerned they would be indirectly bound to regimes which they had not ratified, 3) the existing process of nominating new POPs is so demanding that there was 
little room or need for the dimension of added risk triggered by climate change, and lastly, 4) integrating the added risk posed by climate change is closely linked to the precautionary principle, thus emphasizing a well-known divide between hazard and risk-based management of chemicals. Addressing multiple stressors is more closely aligned to the hazard approach and more precautionary in nature, as it emphasizes the inherent problematic properties of a chemical and its potential effects. Whereas a risk-based approach, emphasizing exposure of a hazardous chemical, i.e. the probability (risk) of an adverse effect occurring, would be challenged by the complexities that multiple stressor interactions represent.

Although it is still early to assess the impact of "the guidance", our analysis suggests that it has so far been shelved and is not actively used when assessing new POPs. Many countries are struggling to ratify and even comply with the existing obligations under the SC. ${ }^{96}$ Thus, it remains an open question whether adding the risk of climate change to the SC in practice would strengthen the protection of human and ecosystem health. Furthermore, the AMAP/UNEP report provided little guidance as to how the coupling of climate change and POPs could be practically implemented locally. The core focus of "the guidance" was on the integration of climate change in the review process. Hence, the question of how climate change and hazardous chemicals can be coupled and practically managed on a local (municipal/ county) level warrants further investigation.

\section{Acknowledgments}

The present study was funded through the Fram Centre flagship research programme "Hazardous Substances-Effects on Ecosystems and Human Health" and NIVA's basic funding from the Research Council of Norway. We are grateful for their support. We thank Dr. Fay Madeleine Farstad, Senior Researcher at CICERO, for thorough review and language editing, and the two anonymous reviewers for valuable comments on the manuscript. We also wish to thank all our informants for sharing their time and valuable insights with us.

\section{NOTES}

1. AMAP, 2019. AMAP Climate Change Update 2019: An Update to Key Findings of Snow, Water, Ice and Permafrost in the Arctic (SWIPA) 2017. Arctic Monitoring and Assessment Programme (AMAP), Oslo, Norway.

2. Ibid. and UNEP/AMAP, 2011. Climate Change and POPs: Predicting the Impacts. Report of the UNEP/AMAP Expert Group. Secretariat of the Stockholm Convention, Geneva.

3. Jianmin Ma, Hayley Hung and Robbie W. Macdonald, "The influence of global climate change on the environmental fate of persistent organic pollutants: a review with emphasis on the Northern Hemisphere and the Arctic as a receptor," Global and Planetary Change 146 (2016): 89-108.

4. See for instance, Daniel Hering et al., "Managing aquatic ecosystems and water resources under multiple stress - An introduction to the MARS project," Science of the Total Environment, 503-504 
(2015): 10-21; Linn M. Persson et al., "Confronting Unknown Planetary Boundary Threats from Chemical Pollution,” Environmental Science E Technology 47 (2013): 12619-12622.

5. E.g. Daniel Hering et al., Science of the Total Environment 503-504.

6. AMAP, 1998. AMAP Assessment Report: Arctic Pollution Issues. Arctic Monitoring and Assessment Programme (AMAP), Oslo, Norway.

7. UNEP/AMAP, 2011. Climate Change and POPs: Predicting the Impacts. Report of the UNEP/AMAP Expert Group. Secretariat of the Stockholm Convention, Geneva.

8. Jianmin Ma et al., Global and Planetary Change 146.

9. Froukje Maria Platjouw, Eirik Hovland Steindal and Trude Borch, "From Arctic Science to International Law: The Road towards the Minamata Convention and the Role of the Arctic Council." Arctic Review on Law and Politics 9 (2018): 226-243.

10. AMAP/UNEP 2011, Daniel Hering et al., Science of the Total Environment, 503-504.

11. See for instance Peeter Nõges et al., "Quantified biotic and abiotic responses to multiple stress in freshwater, marine and ground waters." Science of the Total Environment 540 (2016): 43-52, and references therein.

12. The guidance on how to assess the possible impact of climate change on the work of the Persistent Organic Pollutants Review Committee (UNEP/POPS/POPRC.9/INF/15) can be accessed through the Stockholm Convention website, http://chm.pops.int/TheConvention/POPsReviewCommittee/Meetings/POPRC9/Documents/tabid/3281/Default.aspx (accessed October 20, 2020).

13. Erlend A. T. Hermansen, Policy window entrepreneurship: the backstage of the world's largest REDD+ initiative." Environmental Politics 24:6 (2015): 932-950.

14. Beatrice I. Crona and John N. Parker, "Network Determinants of Knowledge Utilization: Preliminary Lessons From a Boundary Organization”, Science Communication 33(4) $448-471,449$.

15. Ibid.

16. Göran Sundqvist et al., "Formalization and separation: A systematic basis for interpreting approaches to summarizing science for climate policy." Social Studies of Science 45:3 (2015): 416-440.

17. Sheila Jasanoff, "States of Knowledge:The Co-Production of Science and the Social Order.", (Routledge 2004)

18. The AC was extending a former collaboration between the Arctic states "the Arctic Environmental Protection Strategy (AEPS)" that was adopted in June 1991; Arctic Environment, Arctic Environmental Protection Strategy, 14 June 1991. Available at http://library.arcticportal.org/1542/1/artic_environment.pdf (accessed October 20, 2020).

19. Arctic Council official webpage: www.arctic-council.org

20. Svein Vigeland Rottem, "The Use of Arctic Science: POPs, the Stockholm Convention and Norway", Arctic Review on Law and Politics 8 (2017): 246-269.; Platjouw et al. Arctic Review on Law and Politics 9 (2018); Svein Vigeland Rottem, Ida Folkestad Soltvedt and Christian Prip, “Arktisk råd i spennet mellom forskning, forvaltning og politikk," Internasjonal Politikk 78:3 (2020): 284-310.

21. Rottem, Arctic Review on Law and Politics 8 (2017); Platjouw et al. Arctic Review on Law and Politics 9 (2018); Rottem et al., Internasjonal Politikk, 78:3 (2020).

22. Status of ratification per 11 October 2020, http://chm.pops.int/

23. As per 9 September 2020, http://chm.pops.int/

24. The fact that only four countries/regional economic integration organizations have nominated chemicals under the Convention reflects according to our informants the highly demanding and cumbersome process of nomination (INF2, INF3). Furthermore, it probably also reflects the fact that most chemicals nominated in the early years of the Convention were well documented and to some extent "dead chemicals", i.e. chemicals no longer in 


\section{From Arctic Science to Global Policy}

use or production. In recent years, more active chemicals have been nominated and thus the nomination process has become harder and demands more resources. Sweden has only made one nomination in 2005, just after the Convention entered into force, but has since kept closely aligned with the EU as a whole.

25. POPRC consists of 31 government-designated experts taking into account factors such as equitable geographical distribution, gender balance and balance between different types of expertise. The members are expected to be experts in chemical assessment or management and the appointment is confirmed by the COP. Each member serves for a term of four years from the date of appointment, and for no more than two consecutive terms. Some countries share membership. More information available at SC webpage: http://chm.pops.int/TheConvention/ POPsReviewCommittee/Membership/tabid/2808/Default.aspx (accessed October 20, 2020).

26. If all efforts have been exhausted without reaching consensus, the decision needs a three-quarter majority from the Parties present. POPs that are listed in the Convention's Annex A are intentionally added/used and must be eliminated from production and use, although exemptions may apply. Those that are listed in its Annex B must be restricted in production and use (some acceptable purposes and exemptions apply), whereas those listed in Annex $\mathrm{C}$ are unintentionally released and must be minimized (elimination if feasible).

27. David W. Cash et al., "Knowledge systems for sustainable development," National Academy of Sciences 100:14 (2003): 8086-8091; Jasanoff, States of Knowledge: The Co-Production of Science and the Social Order (2004).

28. Sundqvist et al., Social Studies of Science 45:3 (2015).

29. Ibid.

30. Ibid.

31. Peter M. Haas, "Epistemic communities," in: The Oxford Handbook of International Environmental Law, eds. Daniel Bodansky, Jutta Brunnée, and Ellen Hey, (Oxford: Oxford University Press, 2007); Peter M. Haas and Casey Stevens, "Organized science, usable knowledge and multilateral environmental governance," in: Governing the Air: The Dynamics of Science, Policy, and Citizen Interaction, eds. Rolf Lidskog and Göran Sundqvist (Cambridge, MA:The MIT Press, 2011).

32. Jasanoff, States of Knowledge: The Co-Production of Science and the Social Order (2004).

33. Michael Callon, "Some elements of a sociology of translation: Domestication of the scallops and the fishermen of St. Brieuc bay," in Power, action and belief: A new sociology of knowledge? ed. John Law (London: Routledge \& Kegan Paul, 1986).

34. Jasanoff, States of Knowledge: The Co-Production of Science and the Social Order (2004).

35. Thomas F. Gieryn, "Boundary-work and the demarcation of science from non-science: Strains and interests in professional ideologies of scientists," American Sociological Review, 48:6 (1983): 781-795; Thomas F. Gieryn, "Cultural boundaries of science: Credibility on the line," (Chicago, University of Chicago Press, 1999).

36. Sheila Jasanoff, "The fifth branch: Science advisers as policymakers," (Cambridge: Harvard University Press, 1990); Jasanoff, States of Knowledge: The Co-Production of Science and the Social Order (2004); David H. Guston, "Stabilizing the boundary between U.S. politics and science: The role of the Office of Technology Transfer as a boundary organization," Social Studies of Science 29:1 (1999): 87-111; David H. Guston, "Between Politics and Science: Assuring the Integrity and Productivity of Research," (Cambridge: Cambridge University Press, 2000); Clark Miller, "Hybrid management: Boundary organizations, science policy, and environmental governance in the climate regime," Science, Technology, E Human Values, 26:4 (2001): 478-500.

37. Sundqvist et al., Social Studies of Science 45:3 (2015).

38. Guston, Social Studies of Science 29:1 (1999); Guston, Cambridge University Press (2000); Miller, Science, Technology, \& Human Values, 26:4 (2001). 


\section{Eirik Hovland Steindal et al.}

39. Erlend A. T. Hermansen et al., "Co-operation or co-optation? NGOs' roles in Norway's International Climate and Forest Initiative," Forest 8:3 (2017): 64.

40. John Gerring, "What is a case study and what is it good for?", American political science review, 98:2 (2004): 341-354.

41. Out of the reports, nine were co-produced by AMAP and other institutions. Seven reports were screened and contained no reference to multiple stressor issues and were thus omitted from the selection.

42. Three nominations were submitted at COP4 in 2011, the year the UNEP/AMAP report was submitted and guidance drafting initiated and has thus been omitted from the selection.

43. Steinar Kvale and Svend Brinkman, "Interviews: Learning the craft of qualitative interviewing," (Oaks, CA: Sage, 2009).

44. Arctic science is here defined as scientific literature, data and results that have been compiled and assessed with an Arctic view, meaning that the Arctic relevance of the data has been considered while being incorporated into the assessment. The data also includes studies from outside the Arctic. The majority of scientists involved in AMAP come from or are associated with the eight Arctic member states.

45. AMAP, 1998, p. 197.

46. Alta Declaration On The Arctic Environmental Protection Strategy, available through University of Oregon: https://iea.uoregon.edu/treaty-text/1997-altadeclarationarcticenvironmentalprotectionstrategyentxt (accessed October 20, 2020)

47. Robie W. Macdonald et al., "The Influence of Global Change on Contaminant Pathways to, within, and from the Arctic," AMAP Assessment 2002, Arctic Monitoring and Assessment Programme (AMAP), Oslo, Norway. Available at: https:/www.amap.no/documents/download/1158/inline (Accessed October 20, 2020).

48. AMAP, 2002, "Executive Summary to the Arctic Pollution 2002 Ministerial Report," p. xi. Available at: https://www.amap.no/documents/download/1158/inline (accessed October 20, 2020).

49. Ibid.

50. Personal communication with former AMAP employee, October 23, 2020 and January 22, 2021.

51. E.g. Robie W. Macdonald et al., AMAP 2002; AMAP, 2004 "Persistent Organic Pollutants in the Arctic." AMAP Assessment 2002, Arctic Monitoring and Assessment Programme (AMAP), Oslo, Norway. Available at: https://www.amap.no/documents/download/1159/ inline (accessed October 20, 2020); AMAP, 2006, “Acidifying Pollutants, Arctic Haze, and Acidification in the Arctic," AMAP Assessment 2006: Arctic Monitoring and Assessment Programme (AMAP), Oslo, Norway (Accessed October 20, 2020); AMAP, 2011, "Mercury in the Arctic," AMAP Assessment 2011, Arctic Monitoring and Assessment Programme (AMAP), Oslo, Norway. Available at: https://www.amap.no/documents/download/989/inline (accessed October 20, 2020).

52. Platjouw et al. Arctic Review on Law and Politics 9 (2018).

53. AMAP, 2015, "AMAP Expert/Assessment Groups: The role of experts, procedures for nominating and supporting experts, appointing reviewers and conducting peer reviews," Available at: https://www.amap.no/documents/download/2294/inline (accessed October 20, 2020)

54. Ibid., 2 .

55. Rottem, Arctic Review on Law and Politics 8 (2017); Platjouw et al. Arctic Review on Law and Politics 9 (2018).

56. Ibid.

57. The Global Coordination Group (GCG) was set up to facilitate the preparation of the global monitoring report and harmonize and coordinate activities and cooperation between the 
regions, comprised of three members from each region, and nominated by the respective regional coordination groups. The mandate was given in decision 4/31 "Global monitoring plan for effectiveness evaluation" where the Global Coordination Group under the Convention was requested to conduct an "Assessment of long-range transport and the effect of variable climate and meteorology on observed trends for persistent organic pollutants". Cited in UNEP/AMAP, "Climate Change and POPs: Predicting the Impacts," (2011), 7. https://www.amap.no/documents/download/3237/inline (accessed October 20, 2020), also available on SC's website: http://chm.pops.int/Portals/0/Repository/COP4/UNEP-POPSCOP.4-31.English.PDF (accessed October 20, 2020).

58. Stockholm Convention COP4, decision 4/31 "Global monitoring plan for effectiveness evaluation” Document available also SC webpages: http://chm.pops.int/Portals/0/Repository/ COP4/UNEP-POPS-COP.4-31.English.PDF (accessed October 20, 2020).

59. Participant list Conference of the Parties of the Stockholm Convention on Persistent Organic Pollutants Fourth meeting in Geneva, 4-8 May 2009; available at file://C:/Users/ EHS/Downloads/UNEP-POPS-COP.4-INF-34-Rev.1.English.pdf (Accessed October 20, 2020)

60. Doris Friedrich, "Circumpolar Legislation on Pollutants: How Effective is Arctic Governance on Global Environmental Threats?" Arctic Yearbook (2016); David Leonard Downie and Terry Fenge, "Northern Lights Against POPs. Combatting Toxic Threats in the Arctic," (Montreal \& Kingston: McGill-Queen's University Press, 2003); Rottem, Arctic Review on Law and Politics 8 (2017); Henrik Selin and Noelle Eckley, "Science, Politics, and Persistent Organic Pollutants: The Role of Scientific Assessments in International Environmental Co-operation," International Environmental Agreements 3 (2203): 17-42; Noelle Eckley Selin and Henrik Selin, "Global Politics of Mercury Pollution: The Need for Multi-Scale Governance," Review of European Community \& International Environmental Law, 15:3 (2006): 258-269.

61. AMAP, 2019. AMAP Strategic Framework 2019+. Arctic Monitoring and Assessment Programme (AMAP), Tromsø, Norway. Accessible at: https://www.amap.no/documents/download/3362/inline (Accessed October 20, 2020); AMAP Work Plan for 2019-2021. Accessible at: https://www.amap.no/documents/download/3361/inline (accessed October 20, 2020); SC, "From Science to Action", webpage dedicated to science-policy interaction, Accessible at: http://www.brsmeas.org/Implementation/ScientificAndTechnicalActivities/From SciencetoAction/Overview/tabid/4749/language/en-US/Default.aspx (accessed October 20, 2020).

62. UNEP/AMAP, “Climate Change and POPs: Predicting the Impacts," 2011.

63. Rottem, Arctic Review on Law and Politics 8 (2017).

64. Stockholm Convention, document UNEP/POPS/COP.5/30, p. 2, (accessed October 20, 2020): http://chm.pops.int/TheConvention/ConferenceoftheParties/Meetings/COP5/COP5Documents/tabid/1268/Default.aspx

65. Interview with employee at the Norwegian Environment Agency, October 31, 2019; and employee at the Swedish Chemicals Agency, December 20, 2019.

66. Interview with employee at the Norwegian Environment Agency, October 31, 2019.

67. Participant list for the Conference of the Parties (COP) of the Stockholm Convention on Persistent Organic Pollutants Fifth meeting Geneva, 25-29 April 2011, file://C:/Users/EHS/ Downloads/UNEP-POPS-COP.5-INF-51-Rev.1.English.pdf (accessed October 23, 2020).

68. Official meeting report from the Conference of the Parties (COP) of the Stockholm Convention on Persistent Organic Pollutants Fifth meeting Geneva, 25-29 April 2011. http:// chm.pops.int/Convention/COP/Meetings/COP5/COP5Documents/tabid/1268/language/ en-US/Default.aspx (accessed October 23, 2020).

69. Rottem, Arctic Review on Law and Politics 8 (2017). 


\section{Eirik Hovland Steindal et al.}

70. This also reflects the fact that Norway has one of the more solid and long-standing government led environmental monitoring frameworks in Europe.

71. Interview with employee at the Norwegian Environment Agency, October 31, 2019.

72. Interview with employee at the Swedish Chemicals Agency, December 20, 2019; John Kingdon, "Agendas, alternatives, and public policies" (2nd ed.) (New York: Longman, [1984]/2003); Elin Lerum Boasson and Dave Huitema, "Climate Governance Entrepreneurship: Emerging findings and a new research agenda," Environment and Planning C: Politics and Space 35:8 (2017): 1343-1361.

73. Personal communication with AMAP employee; Interview with employee at the Swedish Chemicals Agency, December 20, 2019; List of participants Stockholm Convention on Persistent Organic Pollutants Persistent Organic Pollutants Review Committee Seventh meeting Geneva, 10-14 October 2011 (UNEP/POPS/POPRC.7/INF/25), file://C:/Users/EHS/ AppData/Local/Temp/UNEP-POPS-POPRC.7-INF-25.English.pdf (accessed October 23, 2020).

74. Rottem (2017) has previously described the close link between the Norwegian delegations and AMAP, which at that point had its offices in Oslo, and received most of its funding from Norway. A delegate from Norway took on the role as a lead drafter of the guidance document.

75. Interview with employee at the Swedish Chemicals Agency, December 20, 2019.

76. Interview with employee at the Norwegian Environment Agency, October 31, 2019.

77. Even though the US has never ratified the Stockholm Convention it is still an active participant in the meetings.

78. Interview with employee at the Norwegian Environment Agency, October 31, 2019.

79. Interview with employee at the Swedish Chemicals Agency, December 20, 2019.

80. The guidance on how to assess the possible impact of climate change on the work of the Persistent Organic Pollutants Review Committee (UNEP/POPS/POPRC.9/INF/15) can be accessed through the Stockholm Convention website, http://chm.pops.int/TheConvention/POPsReviewCommittee/Meetings/POPRC9/Documents/tabid/3281/Default.aspx (accessed October 20, 2020)

81. The report was not a purely scientific product in the sense that only scientists had been involved in its development, as experts from UNEP, AMAP and NGOs co-authored and contributed to the report. Among the scientific authors, they were predominantly researchers working in Norway, Sweden and Switzerland. In the development of the guidance the authors also supplemented with new scientific studies and grey literature, although it is stated to "exemplify impacts that were (already) predicted by UNEP/AMAP 2011".

82. Pamelay D. Noyes et al., "The toxicology of climate change: Environmental contaminants in a warming world," Environment International, 35:6 (2009): 971-986.

83. POPRC, 2013, "POPRC-9/8: Guidance on how to assess the possible impact of climate change on the work of the Persistent Organic Pollutants Review Committee, decision 9/8, Annex 1" (UNEP/POPS/POPRC.9/INF/15), available through the Stockholm Convention website, http://chm.pops.int/Convention/POPsReviewCommittee/LatestMeeting/POPRC9/ POPRC9Documents/tabid/3281/Default.aspx (accessed October 23, 2020); Interview with employee at the Swedish Chemicals Agency, December 20, 2019.

84. Still, there are many similar examples of large guidance and supporting documents being processed and adopted by MEA COPs, e.g. the Minamata Convention on Mercury.

85. Interview with employee at the Swedish Chemicals Agency, December 20, 2019.

86. POPRC, 2013, "POPRC-9/8: Guidance on how to assess the possible impact of climate change on the work of the Persistent Organic Pollutants Review Committee, decision 9/8, Annex 1" (UNEP/POPS/POPRC.9/INF/15), available through the Stockholm Convention 
website, http://chm.pops.int/Convention/POPsReviewCommittee/LatestMeeting/POPRC9/ POPRC9Documents/tabid/3281/Default.aspx (accessed October 23, 2020).

87. One of our informants stated that they made sure the decision also referred to the complete guidance, not only the simplified approach, attempting to avoid the policy being watered down (Interview with employee at the Swedish Chemicals Agency, December 20, 2019); In the same decision it was decided to forward the recommendations to the COP for "consideration" at its seventh meeting (9/8-3).

88. Bruno Latour, “The pasteurization of France," (Harvard University Press, 1988).

89. In the Stockholm Convention it is referred to as the 'precautionary approach' with reference to principle 15 in the Rio Declaration on Environment and Development, also referred to as the 'precautionary principle'. In the text of Principle 15 of the Rio Declaration, it is also referred to as the 'precautionary' approach.

90. Interview with employee at the Norwegian Environment Agency, October 31, 2019.

91. Theodore M. Porter, "Trust in Numbers," (Princeton University Press, 1995).

92. Interview with employee at the Norwegian Environment Agency, October 31, 2019.

93. Sheila Jasanoff, "Restoring reason: Causal narratives and political culture," In: Organizational Encounters with Risk, eds. Bridget Hutter and Michael Power (Cambridge: Cambridge University Press, 2005).

94. Jacqueline Peel, "Precaution - A matter of principle, approach or process?" Melbourne Journal of International Law, 5 (2005): 483.

95. Personal communication with two employees at the Norwegian Environment Agency, January 10, 2018.

96. See for instance: IPEN (Int. NGO) Stockholm Convention National Implementation Reviews 2017-2018, available at: https://ipen.org/sites/default/files/documents/ipen-stockholm-nat-impl-reviews-v1_1-en.pdf (accessed October 23, 2020); Global Environment Facility, "Guidelines for reviewing and updating the NIP under the Stockholm Convention on POPs," (GEF/C.39/Inf.5), Council Meeting November 16 - 18, 2010 Washington, D.C, https://www.thegef.org/sites/default/files/council-meeting-documents/C.39.Inf_.5_Guidelines_for_NIP.Final_1.pdf (accessed October 23, 2020). 